\title{
KNOWLEDGE, ATTITUDE AND PRACTICES OF ORAL HEALTH AMONG RURAL CHILDREN OF GOGI VILLAGE, KARNATAKA
}

\author{
Amitha M. Hegde1., Anisha Keshan²., *Nikhitha Aswath.P2 and Parvathy Chandra² \\ Department of Pedodontics and Preventive Dentistry, A B Shetty Memorial Institute of \\ Dental Sciences, Mangalore
}

DOI: http://dx.doi.org/10.24327/ijrsr.2017.0803.0088

\begin{tabular}{l}
\hline ARTICLE INFO \\
\hline Article History: \\
Received 17 th December, 2016 \\
Received in revised form $12^{\text {th }}$ \\
January, 2017 \\
Accepted $04^{\text {th }}$ February, 2017 \\
Published online $28^{\text {th }}$ March, 2017
\end{tabular}

Key Words:

Oral Health, accessibility, rural children, Gogi.

\begin{abstract}
This study was aimed to evaluate the knowledge, attitude and practices of rural children towards oral health. Children $(n=100)$ between the age group of 6 to 8 years, who attended the Government school in Gogi village on the day of screening were recruited into the study. The subjects completed a questionnaire that was aimed to evaluate young children's oral health knowledge, attitude and practices. In the present study, $86 \%$ children were using tooth brush, $92 \%$ of the children were unaware of emergency management of avulsed tooth and that $91 \%$ reported that they have never visited the dentist. $47 \%$ stated lack of access to oral health care as the major reason for not visiting a dentist. Hence we conclude that oral health awareness and knowledge level among rural children in Gogi village was poor and needs to be improved. Need for School dental health programmes is highly recommended which incorporates the need of the population.
\end{abstract}

Copyright (C) Amitha M. Hegde et al, 2017, this is an open-access article distributed under the terms of the Creative Commons Attribution License, which permits unrestricted use, distribution and reproduction in any medium, provided the original work is properly cited.

\section{INTRODUCTION}

As the Father of our nation Mahatma Gandhi rightly puts it "The future of India lies in its villages. If the village perishes India will perish too." About $72 \%$ of the Indian population resides in rural areas with minimal or no access to private dental health sector. Along with financial up gradation and selfsufficiency of villages, personal health care attitudes of rural population also must be improved in order to create a healthy India. It is of utmost importance that the rural population of India needs to be given a lot of attention in oral and dental health education programs in an effort to reduce the rural urban disparities in terms of health (Azodo CC et al, 2013).

Oral health knowledge is considered to be an essential prerequisite for Health-related practices and studies have shown that there is an association between increased knowledge and better oral health. Those who have assimilated the knowledge and feel a sense of personal control over their oral health are more likely to adopt self-care practices (R. Freeman, 1991).

The subjects of this study were from Gogi which is situated in Gulbarga tehsil and located in Gulbarga district of Karnataka harbouring 338 families with a total population of 1891(Census 2011). The area was chosen due to its ideal rural setup with isolated clusters of villages of varied socioeconomic and educational status. The area has no dental facilities and relatively less general health facilities as compared to urban areas of the province. There are no studies till date which investigates the Knowledge attitude and practices towards oral health. Hence this study is a first step towards providing a base line data for further research in this arena.

\section{MATERIAL AND METHODS}

This cross sectional study was carried out in august 2014. The participants for this study were selected by convenience sampling from a government schools. Letter was sent to the selected school explaining the purpose of the study and the procedures that would be followed during its conduct.

The inclusion criteria for this study were children aged 6-8 years. A convenience sample of grade 1 to grade 3 school children was selected. A total of 100 students were invited to participate in this study, of which the data were collected using a self structured close ended questionnaire.

The questionnaire included 20 items designed to evaluate the knowledge, practice and attitude of young school children residing in rural population regarding oral health and oral health practices. The subjects were asked to respond to each item according to the response format provided at the end of each question. The questionnaire was typed in English only and 
was not translated. One of the investigators was always available during the completion of the questionnaire, and the participants were encouraged to approach him whenever they needed clarification at any point.

The questionnaire was designed to evaluate

1. Oral health knowledge, attitudes and selfcare practices;

2. Dietary practices

3. Utilization of services.

\section{RESULTS}

\section{Oral Health Knowledge, Attitudes and Self Care Practices}

A total of 100 children in the age group 6 to 8 years with a mean age of 7 years were screened, of this $45 \%$ were males and $55 \%$ were females.

The oral hygiene habits of our study sample indicated that $14 \%$ of the children would brush their teeth twice per day, whereas $86 \%$ would brush only once per day before breakfast. $87 \%$ of the children used tooth brush to clean their teeth while $9 \%$ reported the use of neem sticks and $4 \%$ children used brick powder. Of the $87 \%$ children who used tooth brush, $88 \%$ children used toothpaste and $12 \%$ used tooth powder. However none of the children were aware of the type of bristle used.

Table 1 Oral Health Knowledge, Attitudes and Self Care Practices

\begin{tabular}{|c|c|}
\hline $\begin{array}{c}\text { Questions } \\
\end{array}$ & $\mathbf{N}(\%)$ \\
\hline \multicolumn{2}{|l|}{ Number of times do you brush? } \\
\hline a. once daily & 86 \\
\hline b. twice daily & 14 \\
\hline \multicolumn{2}{|l|}{ Oral hygiene aids used? } \\
\hline a. tooth brush & 87 \\
\hline b. neem stick & 9 \\
\hline c. brick powder & 4 \\
\hline \multicolumn{2}{|l|}{ Medium used with tooth brush? } \\
\hline a. tooth paste & 88 \\
\hline tooth powder & 12 \\
\hline c. brick powder & - \\
\hline \multicolumn{2}{|l|}{ Other oral hygiene aids? } \\
\hline a. Tongue cleaner & 7 \\
\hline Mouthwash & 11 \\
\hline any other & - \\
\hline d. none & 82 \\
\hline \multicolumn{2}{|l|}{ Brushing technique? } \\
\hline a. round (in circles) & 10 \\
\hline to and fro & 86 \\
\hline c. don't know & 4 \\
\hline \multicolumn{2}{|l|}{ bristles of toothbrush? } \\
\hline a. hard & 41 \\
\hline b. $\quad$ soft & 16 \\
\hline medium & 15 \\
\hline d. don't know & 28 \\
\hline \multicolumn{2}{|c|}{$\begin{array}{l}\text { What will you do if your tooth falls off } \\
\text { during an accident? }\end{array}$} \\
\hline a. Take the tooth to the dentist & $\begin{array}{c}1 \\
81\end{array}$ \\
\hline b. Throw the tooth & $\begin{array}{l}81 \\
12\end{array}$ \\
\hline c. Don't know & 12 \\
\hline \multicolumn{2}{|c|}{$\begin{array}{l}\text { Do you know that a tooth that falls off due to } \\
\text { an accident can be saved? }\end{array}$} \\
\hline a. Yes & $\begin{array}{c}8 \\
92\end{array}$ \\
\hline b. No & \\
\hline \multicolumn{2}{|c|}{ Do you smoke cigarette or chew pan/gutka? } \\
\hline a. Yes & 62 \\
\hline b. No & 38 \\
\hline \multicolumn{2}{|l|}{ Is tobacco injurious to health? } \\
\hline a. Yes & 45 \\
\hline No & 55 \\
\hline
\end{tabular}

$82 \%$ children did not use any additional oral hygiene aids whereas $7 \%$ used tongue cleaner and $11 \%$ used mouth wash.

$86 \%$ children used horizontal scrub technique to clean their teeth while $10 \%$ used fones technique and $4 \%$ were unaware of the technique used.

When children's knowledge about emergency management of avulsed tooth was assessed, it was found that $92 \%$ of the children didn't know that an avulsed tooth can be saved and $81 \%$ of the children would throw away a tooth if it falls off during an emergency; of the $19 \%$ of the children who were aware that an avulsed tooth could be saved, $51 \%$ weren't aware of the means to carry it to the dentist. Only $45 \%$ of the children were aware that tobacco was injurious to health (Table1).

\section{Dietary Practices}

When the dietary practices were assessed it was found that $62 \%$ of children consumed sweets once a day $25 \%$ children consumed more than once and $13 \%$ consumed sweets once a week. Only $18 \%$ of the children consumed sweets during meals while the rest of the children consumed sweets anytime of the day (Table 2).

Table 2 Dietary Practices

\begin{tabular}{cc}
\hline \multicolumn{1}{c}{ Questions } & N(\%) \\
\hline how many times do you eat sweets? & 62 \\
a. once everyday & 25 \\
b. more than once a day & 13 \\
c. once a week & \\
when do you usually eat sweets? & 18 \\
a. during meals & 82 \\
b. anytime & 69 \\
do you drink soft drinks? & 31 \\
a. yes & 8 \\
b. no & 14 \\
if yes, how frequently? & 34 \\
a. 1 to 3 times a day & 35 \\
b. more than 3 times a day $\quad 10$ \\
c. once a day \\
d. rarely \\
e. not at all \\
do you rinse your mouth after having sticky food? \\
a. Yes \\
b. No & 83 \\
\hline
\end{tabular}

Table 3 Utilization of Services

\begin{tabular}{ll}
\hline \multicolumn{1}{c}{ Questions } & N(\%) \\
\hline have you ever visited a dentist? & 9 \\
a. yes & 91 \\
b. no & 5 \\
if yes, for what reason? & 4 \\
a. tooth pain & - \\
b. crooked teeth & - \\
c. routine dental checkup & - \\
d. to clean teeth & 47 \\
e. any other & 37 \\
if no, why? & 7 \\
a. there is no dentist near my house & 9 \\
b. I never had a tooth problem & \\
c. It is very expensive & 9 \\
d. Dental problems are not that important & 16 \\
What do you do if you have a tooth pain? & 8 \\
a. visit a dentist & 67 \\
b. keep a clove & \\
c. apply kerosene & \\
d. any other &
\end{tabular}




\section{Utilization of services}

It was observed that $91 \%$ reported that they have never visited the dentist. of the $9 \%$ children who had visited a dentist, $4 \%$ went for a dental visit for pain and $5 \%$ children visited a dentist complaining of crooked teeth. Instead of visiting a dentist, $91 \%$ of the children used household methods like placement of clove or apply kerosene to relieve dental pain. The most common reason for not visiting a dentist was absence of any dental practitioner in their locality (47\%). $9 \%$ of the children did not think dental treatment was important and $7 \%$ thought dental treatment is expensive (Table 3 ).

\section{DISSCUSSION}

In India, data on oral health behavior amongst rural children is limited; henceforth the present study intended to provide such information with regards to children aged 6 to 8years old residing in Gogi a rural sector of India. In the present study, $86 \%$ children were using tooth brush and $9 \%$ of children were using neem stick to clean their teeth. The percentage of children using tooth brush was in accordance to the study done by $\mathrm{WHO}$, in a rural population in Uttaranchal state where $83 \%$ of the children used brushes (WHO, 2006). This increase in percentage of children using tooth brush as an oral hygiene aid could be because of increased awareness regarding basic oral hygiene measures. Some children resorted to the use of charcoal, sand or chalk powder as a medium to clean their teeth. This holds true with the study done by Mahesh Kumar et al in Chennai, where in their study population also children resorted to the use of charcoal as a medium to brush their teeth (Mahesh Kumar P, 2005). Further, it was found that only $7 \%$ of the children brush twice-daily. This finding is very much less when compared to the study by Harikiran et al (2008), where it was $38.5 \%$ and WHO (2006) study where it was $49 \%$. However the use of other recommended oral hygiene aids such as tongue cleaner and mouth wash was minimal; this could be due to lack of oral health education and/or cost of such aids.

Knowledge about emergency management of avulsed teeth was extremely low in the present study. However data regarding knowledge amongst rural Indian children regarding the same was not available.

Tobacco addiction is emerging as a big threat among rural children. A recent study conducted by Narain et al (2011) reported a downward shift in the age at initiation of tobacco uptake and rising prevalence among girls. Hence it is very essential to assess the awareness about ill effects of tobacco usage amongst rural children. In our present study only $45 \%$ children were aware about the ill effects and this could be a leading cause for their uptake of the habit at a very early age.

$82 \%$ of children resorted to snacking between the meals. This dietary habit could be attributed to lack of knowledge amongst the rural children about factors that could lead to dental caries.

Lack of access to oral health care also contributes to the profound and persistent oral health disparities that exist in the rural areas of India. In our study we observed that $91 \%$ reported that they have never visited the dentist. 47\% stated lack of access to oral health care as the mojor reason for not visiting a dentist. Amongst $9 \%$ of the study subjects who visited a dentist pain was the major reason for the last dental visit. Similar results were seen in the study carried out by
Meng et al (2007). In developing countries like India, cost of the treatment is a very important factor that effects the oral health care utilization. Low income or low educational qualification has for a long time been well recognized as a barrier to utilization of oral health care (Guay AH et al, 2004). Instead of visiting a dentist, $91 \%$ of the children used household methods like placement of clove or apply kerosene to relieve dental pain. $9 \%$ of the children did not think dental treatment was important and $7 \%$ thought dental treatment is expensive.

\section{CONCLUSION}

Results of this study prove that oral hygiene habits, oral health awareness and knowledge level among rural children in gogi village is poor and needs to be improved. Parents and teachers need to be informed, motivated about dental care so that their attitudes change. Based upon these findings, the establishment of a school-based oral health education program in rural school children, including parents and teachers is recommended. Also oral health education programs could be included in the school curriculum for the children to emphasis a positive attitude toward oral health. Utilization of oral health services among the rural population has been found to be influenced by lack of accessibility. The services provided in the programs should be based on the felt needs of the rural population, so that both attendance and the utilization of dental services can be increased, thereby improving the oral health status of the population.

\section{References}

1. Azodo CC, Amenaghawon OP (2013): Oral hygiene status and practices among rural dwellers. Eur J Gen Dent; 2:42-5.

2. R. Freeman, J. Maizels, M.Wyllie, and A. Sheiham (1991): "The relationship between health related knowledge, attitudes and dental health behaviors in 1416 year-old adolescents," Community Dental Health; 10(4): 212-19.

3. Population Census 2011, Gogi Population - Gulbarga, Karnataka Available: www.census2011.co.in/data/ village/620214-gogi-karnataka.html.

4. Oral Health Status in rural child population: Promotional \& Interventional Strategies. A GOI-WHO Collaborative Programme 2006-07. www.whoindia.org/en/.../Section 30_1453.htm -

5. Mahesh Kumar P, Joseph T, Varma RB, Jayanthi M (2005): Oral health status of 5 years and 12 years school going children in Chennai city - An epidemiological study. J Indian Soc Pedod Prev Dent; 23(1):17-22.

6. Harikiran AG, Pallavi SK, Hariprakash S, Ashutosh, Nagesh KS.(2008): Oral health-related KAP among 11 to 12-year-old school children in a Government-aided Missionary School of Bangalore city. Indian J Dent Res [serial online]; 19(3):236-42.

7. Narain R, Sardana S, Gupta S, Sehgal A. (2011) Age at initiation \& prevalence of tobacco use among school children in Noida, India: A cross-sectional questionnaire based survey. Indian Journal of Medical Research; 133(3):300.

8. Meng X, Heft MW, Bradley MM, Lang PJ.(2007): Effect of fear on dental utilization behaviors and oral 
health outcome. Community Dent Oral Epidemiol; 35:292-301.
9. Guay AH. (2004): Access to dental care: Solving the problem for underserved populations. J Am Dent Assoc; 135:1599-605.

\section{How to cite this article:}

Amitha M. Hegde et al.2017, Knowledge, Attitude and Practices of Oral Health Among Rural Children of Gogi Village, Karnataka. Int J Recent Sci Res. 8(3), pp. 16156-16159. DOI: http://dx.doi.org/10.24327/ijrsr.2017.0803.0088 